\title{
Mutant IDH1 Inhibitor DS-1001
}

National Cancer Institute

\section{Source}

National Cancer Institute. Mutant IDH1 Inhibitor DS-1001. NCI Thesaurus. Code C148134.

An orally available inhibitor of isocitrate dehydrogenase type 1 (IDH 1; IDH-1; IDH1 [NADP+] soluble) mutant forms, including substitution mutations at the arginine in position 132, IDH1(R132) (IDH1-R132), with potential antineoplastic activity. Upon administration, mutant IDH-1 inhibitor DS-1001 specifically inhibits certain mutant forms of IDH1, thereby inhibiting the formation of the oncometabolite 2-hydroxyg lutarate ( $2 \mathrm{HG}$ ) from alpha-ketog lutarate (a-KG). This prevents $2 \mathrm{HG}$-mediated signaling and leads to both an induction of cellular differentiation and an inhibition of cellular proliferation in tumor cells expressing IDH1 mutations. IDH1(R132) mutations are highly expressed in certain malignancies, including gliomas; they initiate and drive cancer growth by both blocking cell differentiation and catalyzing the formation of 2HG. DS-1001 minimally targets and affects wild-type IDH1, which is expressed in normal, healthy cells. 